\title{
A UTILIZAÇÃO DA MEDIAÇÃO COMO FORMA DE EFETIVAÇÃO AO ACESSO À JUSTIÇA E O PRINCÍPIO DA DIGNIDADE DA PESSOA HUMANA
}

\section{USE OF MEDIATION AS EFFECTIVE WAY TO ACCESS WILL JUSTICE AND THE PRINCIPLE OF HUMAN DIGNITY}

\begin{abstract}
DiRCEU PEREIRA SIQUEIRA
Pós-doutor em Direito pela Faculdade de Direito da Universidade de Coimbra (Portugal); Doutor e Mestre em Direito Constitucional pelo Centro de Pós-Graduação da ITE/Bauru - SP; Professor Permanente do Programa Pós-graduação em Ciências Jurídicas - Mestrado em Direito no Centro Universitário de MaringálPR - UniCesumar; Professor nos Cursos de Graduação em Direito no Centro Universitário de Araraquara - UNIARA e no Centro Universitário de Bebedouro - UNIFAFIBE dpsiqueira@uol.com.br
\end{abstract}

Caroline Zanetti Paiva Mestranda no Programa de Pós-graduação em Ciências Jurídicas - Mestrado em Direito pelo Centro Universitário de Maringá-PR - UniCesumar; Advogada. caroline.paiva.adv@hotmail.com

\section{RESUMO}

Conflitos são inerentes a todo e qualquer ser humano, no entanto, a forma como os mesmos serão dirimidos é que determinará as consequências do imbróglio. A mediação, por se tratar de uma forma de autocomposição assistida onde as partes são estimuladas a visualizarem e delinearem o conflito e encorajadas a solucionarem por si seus problemas, visa amenizar as consequências do imbróglio e o alcance efetivo da resolução do conflito. Garantir o respeito ao princípio da dignidade da pessoa humana é garantir um efetivo acesso à justiça que garanta aos conflitantes o mínimo de conseqüência possívela fim de preservar seus direitos fundamentais.

Palavras-chave: Acesso à Justiça; Dignidade da Pessoa Humana; Mediação.

\begin{abstract}
Conflicts are inherent to all and any human being, however, the form with that the same ones will be settled is that will determine the consequences of the problem. Mediation, because it is a form of autocomposition assisted where parts are encouraged to view and delineate the conflict and encouraged to solve their problems by themselves, it seeks to soften the consequences of the conflict and the effective reach of the resolution of the conflict. To guarantee the respect to the beginning of the human person's dignity is to guarantee a cash access to the justice that guarantees to the conflicting ones the minimum of consequence in order to preserve their fundamental rights.
\end{abstract}

Keywords: Access to Justice; Human Dignity; Mediation.

\section{SUMÁRIO}

INTRODUÇÃO; 1 BREVE CONSIDERAÇÃO SOBRE OS MEIOS ALTERNATIVOS DE RESOLUÇÃO DE CONFLITOS; 2 MEDIAÇÃO; 3 MEDIAÇÃO SOB A PERSPECTIVA DA DIGNIDADE DA PESSOA HUMANA E DO ACESSO À JUSTIÇA; CONCLUSÃO; REFERÊNCIAS 


\section{INTRODUÇÃO}

O homem por si só detém necessidades, bem como valores que os diferem dos demais seres humanos. Cada um possui seus interesses que nem sempre encontram amparo no direito bem como na moral.

Uma vez escassos os bens para a satisfação dessas pretensões, ou até mesmo pela coincidência desta pretensão com a de outrem, poder-se-á dizer que tal pretensão foi resistida, dando ensejo assim a um conflito.

Com a insurgência do mesmo, é comum as partes se socorrem ao poder judiciário, ocorre, porém, que face aos desgastes deste órgão, seja pela sua morosidade, ineficiência, onerosidade ou até mesmo pela falta de estrutura necessária, o acesso à justiça fica prejudicado assim como a garantia à dignidade humana de todos os envolvidos.

0 presente trabalho visa abordar quanto aos meios alternativos de resolução de conflito, em especial a mediação, instrumento efetivo para dirimir conflitos que envolvam passado, presente e futuro, pois visa restabelecer o diálogo entre as partes encorajando-as a resolverem por si só seus problemas, a fim de garantir o efetivo acesso à justiça assim como promover a dignidade humana.

Para tanto, primeiramente, aborda de uma forma sintetizada os meios alternativos de resolução de conflitos, posteriormente, analisa o instrumento mediação, conceituando-o e qualificando-o, e, em seguida, busca demonstrar a utilização da mediação como forma de efetivação do princípio da dignidade da pessoa humana assim como do acesso à justiça.

Para cumprir com tal propósito, utilizou-se da metodologia de pesquisa bibliográfica.

\section{BREVE CONSIDERAÇÃO SOBRE OS MEIOS ALTERNATIVOS DE RESOLUÇÃO DE CONFLITOS}

Os meios alternativos de resolução de conflito são instrumentos facultativos, para que as partes resolvam seus imbróglios, sem a intervenção Estatal. A sociedade tem como regra socorrer-se ao poder judiciário, paradigma que requer alterações.

Com a possibilidade de utilização desses instrumentos, surge uma nova proposta, uma nova possibilidade para a satisfação do litígio, de forma mais flexível, informal e mais célere. 
Os meios alternativos de resolução de conflitos podem ser classificados como meios autocompositvos, quando as próprias partes envolvidas no conflito trazem uma solução ao imbróglio, como é o caso da conciliação, mediação e negociação, como em meios heterocompositivos, quando a solução é trazida por um terceiro, como é o caso da arbitragem.

Tais mecanismos constituem uma proposta promissora para amenizar a crise que assombra o Poder Judiciário e acima de tudo viabilizar maior garantia aos direitos de personalidade dos envolvidos e a dignidade humana de cada um, vez que contribuem para uma pacificação social, estimulando as partes a solucionarem por si próprias suas diferenças.

A atualidade presencia uma crise jurisdicional, é perceptível aos olhos de todos que o Estado não vem cumprindo satisfatoriamente com seu papel no que diz respeito à garantia efetiva da prestação jurisdicional. Sem contar as dificuldades secundárias, tais como; altos valores das custas para a mantença do processo, honorários advocatícios e periciais, morosidade na tramitação dos autos, dentre outros fatores, que inviabilizam a segurança de direitos personalíssimos e a dignidade humana de cada cidadão.

Nessa mesma visão defende Bezerra que:

Tecnicamente, aponta como obstáculos à efetividade do acesso à justiça, as custas que inviabilizam as pequenas causas, o tempo gasto no processo, (a demora da justiça é injustiça), a utopia da igualdade das partes perante a lei e os processos, o escasso conhecimento do homem comum a respeito da maneira de ajuizar as demandas, e até a obrigatoriedade de alguns sistemas como o nosso, de contratação de advogados, o que gera honorários de custo elevado, tudo isso é obstáculo a um efetivo acesso à justiça. ${ }^{1}$

Por outro lado os meios alternativos de resolução de conflitos contam com características distintas e essenciais para que sua prática seja cada vez mais eficaz. Além de propiciar a pacificação social, vez que busca a prevenção de futuros conflitos através do diálogo entre as partes, viabiliza também a continuidade da relação após o conflito.

Via de regra quando da aplicação de tais meios, prevalece a confidencialidade, o sigilo entre as sessões e o teor das mesmas, gerando assim um maior conforto e segurança às partes que se encontram envolvidas.

Um dos pontos que merece destaque é quanto à informalidade no procedimento de alguns métodos, como o da mediação, que não conta com formas predeterminadas ou formas

1 BEZERRA, Paulo Cesar Santos. Acesso à justiça: um problema ético-social no plano da realização do direito. Rio de Janeiro: Renovar, 2001, p.128. 
rígidas a serem seguidas, destacando-se, assim, a simplicidade dos atos e a liberdade das partes em determinar todos os seus aspectos, características de extrema importância para uma rápida e satisfatória solução do litígio.

Como frisa Cappeletti: "procedimentos complicados, formalismo, ambientes que intimidam, como o dos tribunais, juízes e advogados, figuras tidas como opressoras, fazem com que o litigante se sinta perdido, um prisioneiro num mundo estranho."2

Pensamento este que corrobora Ivan Ruiz:

Já se viu que a formalidade é necessária, mas o exagero formalismo é desnecessário, servindo tão-somente para procrastinar o desenvolvimento dos atos processuais. A deformalização é a tendência do direito processual, pois visa dar pronta solução ao conflito de interesses, no mais breve espaço de tempo possível. $^{3}$

Sentir-se recuado, oprimido e amedrontado, limita a atuação do indivíduo, o que certamente atrapalha a efetiva prestação da justiça e a satisfação do litígio.

Propicía também um custo reduzido quando comparado aos de um processo judicial, sem contar principalmente na diminuição de desgastes emocionais, pois o tempo de duração do procedimento certamente é inferior do que dos procedimentos tradicionais.

Afinal, o incomodo gerado pelo arrastar da causa é impactante às partes, gerando sofrimento, angústia e incômodo.

Para o doutrinador Luiz Guilherme Marioni, ignorar a razoabilidade de tempo do trâmite do processo vai além da violação de direito constitucional, afeta sentimentos, acarretando decepção e sofrimento:

Se o tempo é a dimensão fundamental da vida humana e se o bem perseguido no processo interfere na felicidade do litigante que o reivindica, é certo que a demora do processo gera, no mínimo, infelicidade pessoal e angústia e reduz expectativas de uma vida mais feliz (ou menos infeliz). Não é possível desconsiderar o que se passa na vida das partes que estão em juízo. 0 cidadão concreto, o homem das ruas, não pode ter os seus sentimentos, as suas angústias e as suas decepções desprezadas pelos responsáveis pela administração da

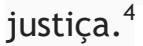

\footnotetext{
${ }^{2}$ CAPPELLETTI, Mauro. Acesso à justiça. Trad. Ellen Gracie Norhfleet. Porto Alegre: Fabris, 1988. p.24. ${ }^{3}$ RUIZ, Ivan Aparecido. Estudo sobre mediação no Direito brasileiro: natureza jurídica e outros aspectos fundamentais. 2003. Tese, Pontifícia Universidade Católica de São Paulo, p.47.

${ }^{4}$ MARINONI, Luiz Guilherme. Tutela antecipatória e julgamento antecipado: parte incontroversa da demanda. 5.ed. São Paulo: Revista dos Tribunais, 2002, p.17.
} 
A justiça tardia não pode ser chamada de justiça, a falta de atenção dada a esse requisito bem como ao sentimento de frustração do cidadão envolvido no imbróglio, evidencia a falha do exercício estatal.

O que se vê com inúmera frequência nos processos judiciais é o clima de adversidade e animosidade entre as partes, características que podem ser extirpadas quando da utilização de meios alternativos, pois estes permitem a preservação e a continuidade das relações envolvidas por intermédio da maior proximidade das partes, especificidade e adequação da solução alcançada, além da celeridade e manutenção do sigilo.

\section{MEDIAÇÃO}

Uma das características principais desse instituto é a possibilidade de criação ou até mesmo a recriação de vínculos. É extremamente válida para questões que tenham passado, presente e futuro e principalmente as que contam com envolvimento emocional.

É muito indicado em conflitos familiares, trabalhistas, cíveis, dentre outros, mas principalmente quando há envolvimento emocional entre as partes ou quando seja entre pessoas do mesmo convívio.

A mediação no Brasil sofreu grande influência histórica, na cultura oriental, tais como os chineses, japoneses e judeus, bem como do ocidente como a Grã-Bretanha, Estados Unidos, Canadá e França, segundo Águida Arruda Barbosa. ${ }^{5}$

Tal instituto surgiu de forma natural, existindo desde tempos imemoriais, onde pode inclusive ser classificada com uma qualidade interna do ser humano, tamanha a naturalidade da prática, no entanto, estudos a respeito são de grande valia para o seu aprimoramento.

A prática já era inclusive defendida por Confúcio anos antes de Cristo, que conforme Junior;

$\mathrm{Na}$ China de Confúcio, que viveu cerca de 550-479 a.C., a justiça era administrada segundo $l i$, que representava o ideal de comportamento permanente de todos os homens. Quando essa regra era quebrada, evitava-se o processo, pois ele era considerado desonroso, na medida em que atentava contra a paz social. Era necessário procurar sempre o compromisso, a conciliação, a solução negociada que acomodasse uma e outra parte. ${ }^{6}$

\footnotetext{
${ }^{5}$ BARBOSA,Águida Arruda. Mediação familiar interdisciplinar. São Paulo: Atlas S/A, 2015, p.7.

${ }^{6}$ RODRIGUES JUNIOR, Walsir Edson. A prática da mediação e o acesso à justiça. Belo Horizonte: Del Rey, 2006, p. 64.
} 
No islamismo a prática também sempre foi difundida, conforme afirma Christopher Moore;

As culturas islâmicas também têm longa tradição de mediação. Em muitas sociedades pastoris tradicionais do Oriente Médio, os problemas eram freqüentemente resolvidos através de uma reunião comunitária dos idosos, em que os participantes discutiam, debatiam, deliberavam e mediavam para resolver questões tribais ou intertribais críticas ou conflituosas. Nas áreas urbanas, o costume local ('urf) tornou-se codificado em uma lei sari'a, que era interpretada e aplicada por intermediários especializados, ou quadis. Estes oficiais exerciam não apenas funções judiciais, mas também de mediação. ${ }^{7}$

No Brasil a mediação teve seu início na década de 90 , no entanto com o objetivo principal de desafogar o Poder Judiciário, que nas palavras de Águida Arruda Barbosa;

A mediação insere-se na busca de redução do distanciamento cada vez mais crescente entre o Judiciário e o cidadão, num primeiro plano, visa-se buscar meios de desafogar o Judiciário, sem nenhuma preocupação em eliminar as causa do imenso número de processos que esmagam os tribunais. ${ }^{8}$

Foi, então, a partir de tal época que passaram a existir os movimentos legislativos em prol do reconhecimento, bem como da definição correta de mediação. Em 1998 surge o Projeto de lei $n^{\circ}$ 4.827/98, de iniciativa da deputada Zulaiê Cobra Ribeiro que, posteriormente, em meados de 2003, conjuntamente com a proposta legislativa realizada por Ada Pellegrini Grinover, deu ensejo ao projeto de lei de mediação.

Trata-se de um projeto de lei com primorosa tecnicidade dada ao texto final da forma consensuada; porém, seu conteúdo visa desafogar o Judiciário, sem nenhuma abrangência capaz de não mais afogá-lo, passando a diluir as causas que ensejam essa crise insustentável. ${ }^{9}$

Foi a curtos passos que a mediação então passou a ser vista não como uma mera forma de auxiliar abarrotamento de processos, mas sim como uma maneira eficaz de dirimir o conflito.

\footnotetext{
${ }^{7}$ MOORE,Christopher. 0 processo de mediação: estratégias práticas para a resolução de conflitos. In RODRIGUES JÚNIOR, Walsir Edson,A prática da mediação e o acesso à justiça. Belo Horizonte: Del Rey, 2006. p. 63.

${ }^{8}$ BARBOSA,Águida Arruda. op. cit., 2015, p. 17.

${ }^{9}$ BARBOSA,Águida Arruda, op. cit. 2015, p. 19.
} 
Assim no ano de 2015 que o citado instituto obteve grandes conquistas. Sancionou-se no respectivo ano, a lei da mediação $n^{\circ}$ 13.140/2015, que entra em vigor no início do ano de 2016 e o novo Código de Processo Civil, que entra em vigência a partir de 17/03/2016.

A Lei de mediação assim como o novo código civil possibilitaram o exercício da mediação judicial e extrajudicial, observando alguns requisitos.

Com as novas legislações a mediação então passa a ser conceituada e positivada e como isso passa, mesmo que timidamente, a ser incentivada. Há assim a determinação de que os tribunais criem centros judiciários de solução consensual de conflitos, para que divulguem apliquem e encorajem a utilização da autocomposição.

Com a positivação deste instituto “[...] a mediação conquista reconhecimento com legítima atividade de implantação desta prática, garantindo a mudança de cultura de litígio passando a cultura da comunicação que prestigia as diferenças." 10

A sociedade sempre depositou no poder judiciário a responsabilidade para extirpação de qualquer conflito, a cultura social ainda visualiza que a adversidade é o melhor caminho para que o problema seja sanado.

Para que tais fatos sejam alterados, inúmeros aprimoramentos deverão existir, desde a divulgação e o incentivo à pratica de tal instituto até ao desenvolvimento de políticas públicas a fim de alterar a cultura adversarial construída ao longo dos séculos.

A lei da mediação, nos termos do parágrafo único do art.1, a define como; Considera-se mediação a atividade técnica exercida por terceiro imparcial sem poder decisório, que, escolhido ou aceito pelas partes, as auxilia e estimula a identificar ou desenvolver soluções consensuais para a controvérsia.

0 instituto da mediação corriqueiramente é confundido com ao da conciliação, no entanto, tratam se institutos completamente distintos. Conceitua José Luiz Bolzan Morais que: "a conciliação se apresenta como uma tentativa de se chegar voluntariamente a um acordo neutro, na qual pode atuar um terceiro que intervém entre as partes de forma oficiosa e desestruturada, para dirigir a discussão sem ter papel ativo"11.

A grande diferença entre os dois institutos mora tanto na atuação do terceiro, conciliador e mediador quanto nos objetivos tencionados com a aplicação de cada instituto. Enquanto aquele possui liberdade para sugerir alternativas para a celebração do acordo, bem como

\footnotetext{
${ }^{10}$ Ibid, p. 3.

${ }^{11}$ MORAIS, José Luiz Bolzan de. Mediação e arbitragem: alternativas à jurisdição. Porto Alegre: Livraria do Advogado, 1999, p.135.
} 
deposita o sucesso do seu trabalho na celebração do acordo, este exerce um papel muito mais complexo, aproximando as partes, para que se escutem e tentem compreender as razões e motivos do outro conflitante, tudo isso sem a emissão de qualquer juízo valorativo, para que então as partes encontrem a melhor solução do seu problema.

Ressalta-se ainda que o maior objetivo da mediação não é a celebração do acordo, que poderá ocorrer ou não, mas sim que as partes consigam restabelecer um diálogo.

Corroborando da mesma idéia, Warat defende que a mediação tem um caráter transformador:

[...] uma forma ecológica de resolução dos conflitos sociais e jurídicos; uma forma na qual o intuito de satisfação do desejo substitui a aplicação coercitiva e terceirizada de uma sanção legal. A mediação é uma forma alternativa (com o outro) de resolução de conflitos jurídicos, sem que exista a preocupação de dividir a justiça ou de ajustar o acordo às disposições do direito positivo. ${ }^{12}$

É como se as partes reconstruíssem o conflito simbolicamente e, por meio desse processo, alcançassem a solução do imbróglio, uma vez que encoraja a autonomia das partes.

Para Haim Grunspun, a mediação "é um processo informal, sem litígio, que tem por objetivo ajudar as partes em controvérsia ou disputa a alcançar aceitação mútua e concordância voluntária."13

Já na visão de Águida Arruda Barbosa;

A mediação é um método que se vale de técnicas de comunicação, adequadas para a escuta qualificada, prestando-se, com muita eficácia, a concretizar o princípio constitucional de proteção à dignidade da pessoa humana e de proteção do Estado. ${ }^{14}$

A autora tem uma visão principiológica da mediação, ao seu ver tal instituo poderá perfeitamente ser caracterizado como um princípio, pois representa a concretude do princípio da dignidade da pessoa humana. Para ela, o princípio da mediação tem laço estreito com o princípio da dignidade da pessoa humana, que por sua vez protege o princípio do livre desenvolvimento da personalidade dentre outros demais princípios.

E ainda afirma que:

\footnotetext{
${ }^{12}$ WARAT, Luis Alberto. 0 ofício do mediador. Florianópolis: Habitus Editora, 2001, p. 05.

${ }^{13}$ GRUNSPUN, Haim. Mediação familiar: o mediador e a separação de cais com filhos. São Paulo: LTR, 2000, p. 13.

${ }^{14}$ BARBOSA,Águida Arruda, op. cit.2015, p. 55.
} 
[...] o reconhecimento teórico da mediação como princípio - e não como procedimento - coaduna-se, perfeitamente, com a orientação principiológica adotada pelo Código Civil de 2002, que acolhe os princípios constitucionais da proteção à família, do livre desenvolvimento da personalidade, e da responsabilidade pelo próximo, concretizados nos princípios da eticidade, da sociabilidade e da operabilidade. ${ }^{15}$

A mediação, caso eleita como um princípio, está inteiramente ligada ao comportamento e jamais a condutas procedimentais, afinal, ninguém rege os comandos para a concretude dos princípios. No entanto, tal posicionamento ainda está longe de ser acatado.

Para que a mediação tenha bons frutos, o bom desempenho da função de mediador é essencial.0 mediador por sua vez se limita na aproximação das partes e os auxilia para ocorrência de um diálogo.

Muito embora pareça simples, inúmeras são as funções que o mediador deverá desempenhar, como explana Calmon:

Favorecer o intercambio de informação, prover de nova informação; ajudar a cada parte a entender a visão da contraparte; mostrar a ambas que suas preocupações são compreendidas; promover um nível produtivo de expressão emocional; manejar as diferenças de percepção e interesses entre os negociadores e outros, inclusive advogado e cliente; ajudar aos negociadores a avaliar alternativas realistas para possibilitar o acordo; gerar flexibilidade; mudar o foco do passado para o futuro; estimular a criatividade das partes, ao induzi-las a sugerir propostas de acordo; aprender a identificar os interesses particulares que cada uma das partes prefere não comunicar à outra; prover soluções que satisfaçam os interesses fundamentais de todas as partes envolvidas. ${ }^{16}$

0 mediador introduz as ferramentas, as possibilidades e seu objetivo é favorecer a um acordo pacífico e satisfatório para ambas as partes envolvidas.

O mediador não decide e as partes não perdem para que alcancem um acordo, porque um mau acordo não e acordo, pois méis cedo ou mais tarde, um mau acordo gerará e a retomada de conflito, visto que um acordo não impões perdas, mas o gerenciamento de opções. ${ }^{17}$

\footnotetext{
${ }^{15}$ Ibid, p. 29.

${ }^{16}$ CALMON, Petrônio. Fundamentos da Mediação e da Conciliação. Rio de Janeiro: Forense, 2007, p.123.

${ }^{17}$ ZAPPAROLLI, Celia Regina. A experiência pacificadora da mediação: uma alternativa contemporânea para a implementação da cidadania e da justiça. In:Mediação de conflitos: pacificando e previnindo a violência. São Paulo: Summus, 2003, p.53.
} 
Afinal, a imposição de uma decisão e um acordo mal formulado tende a ser infrutífero, razão pela qual a mediação preza sempre pela busca do interesse das partes e não de soluções.

É de extrema importância que o mediador se valha de técnicas de comunicação qualificada, pois “qualquer comunicação inadequada entre os sujeitos de direito exalta conflitos potenciais, acirrando o sofrimento. ${ }^{" 18} 0$ mediador ocupa uma função pedagógica, pois é responsável para que seja retirado o sentimento destrutivo que se encontra intrínseco em cada conflitante, a fim de que o sentimento de pacificação seja nutrido.

A mediação busca muito mais a pacificação das partes do que a do próprio conflito, enxergando a disputa com outros olhos e visa, acima de tudo, extirpar ou amenizar a causa que levou as partes a litigarem.

Mediação é a linguagem do terceiro milênio, e a eficácia de seu emprego resulta em construção de passarelas entre pessoas e grupos, derrubando qualquer muro, que ainda exista, inclusive simbólico, a exemplo do preconceito. Quando a comunicação acontece, há uma transformação do conflito, positivamente, pois suas potencialidades transformam-se em força motriz para a renovação. Trata-se do alcance da liberdade perdida. ${ }^{19}$

Tal instituto tem o intuito de transformação do conflito, e principalmente das partes litigantes, reforçando a individualidade de cada problema e os sentimentos envolvidos. “Mediante esse procedimento, as partes são introduzidas à cultura da administração pacífica de seus próprios problemas, à conversão de um conflito de interesses em possibilidades reais." 20 Quando diligenciada corretamente é capaz de tornar o direito muito mais acessível às partes, garantindo a preservação de direitos de personalidade e a garantia da dignidade humana dos conflitantes.

É necessário assim visualizar que não somente a via jurisdicional é competente para elucidar conflitos, é como ensina Giordano; “La responsabilidad jurídica no esla única. Si reducimos todo ella es porque pensamos que laley es perfecta, y

\footnotetext{
${ }^{18}$ BARBOSA,Águida Arruda, op.cit., 2015, p.56.

${ }^{19}$ BARBOSA, Águida Arruda. Mediação familiar interdisciplinar. São Paulo: Atlas S/A, 2015, p. 34.

${ }^{20}$ ZAPPAROLLI, A experiência pacificadora da mediação: uma alternativa contemporânea para a implementação da cidadania e da justiça. In: MUZSKAT, Malvina Ester (Org.). Mediação de conflitos: pacificando e prevenindo a violência. São Paulo: Summus, 2003, p. 53.
} 
yahemosseñaladocuántasfisurasexisten em el sistema judicial." ${ }^{21}$ Como a autora afirma a legislação não é perfeita, existem lacunas e a decisão proferida nem sempre será a mais justa.

Por fim, cumpre esclarecer que as soluções obtidas a partir da mediação são mutuamente satisfatórias, vez que não se originaram de qualquer imposição, mas sim do consenso surgido entre as partes. Pois somente as partes, que vivenciaram de fato o conflito, poderão indicar o melhor caminho para a solução.

Sem contar que a mediação possibilita que as partes enxerguem sua capacidade de resolução de problemas, sentindo-se de autônomas, fato que as encoraja à pacificação social.

\section{MEDIAÇÃO SOB A PERSPECTIVA DA DIGNIDADE DA PESSOA HUMANA E DO ACESSO À JUSTIÇA}

A definição exata do princípio da dignidade da pessoa humana é tarefa árdua até o presente momento. Conforme Luiz Roberto Barroso ${ }^{22}$ tal instituto teve sua formação vinculada a evolução histórica, que alcançou o seu ápice no século XX, principalmente no período após a Segunda Guerra Mundial, onde a ideia de dignidade humana foi incorporada ao discurso político dos vencedores da batalha se tornando um fim a ser alcançado por instituições nacionais e internacionais.

O princípio em questão teve suas raízes na doutrina cristã, no humanismo e principalmente na filosofia lluminista, que teve seu ápice em Kant. ${ }^{23}$ De acordo com o filósofo; "quando uma coisa tem um preço, pode por-se em vez dela qualquer outra como equivalente, mas quando uma coisa está acima de todo o preço, e portanto não permite equivalente, então ela tem dignidade.". ${ }^{24}$

Para Kant, "o Homem, como ser racional, dotado de autonomia moral, constitui sempre um fim em si mesmo e nunca um meio para o atingimento de algum outro fim, não tendo por isso preço, mas dignidade."25

\footnotetext{
${ }^{21}$ GIORDANO, Consuelo Ares de. Mediación, conflictos y soluciones razonables. Mendonza: Jurídicas cuyo, 2004, p. 75. Trad. "A responsabilidade jurídica não é única. Se assim fizermos é como se estivéssemos afirmando que a lei é perfeita, e como já observamos há várias fissuras no sistema judicial."

${ }^{22}$ BARROSO, Luíz Roberto. A dignidade da pessoa humana no direito constitucional contemporâneo: a construção de um conceito jurídico à luz da jurisprudência mundial. Belo Horizonte: Fórum, 2013, p. 54.

${ }^{23}$ SARMENTO, Daniel. Direitos fundamentais e relações privadas. Rio de Janeiro: Lumen Juris, 2004, p.108.

${ }^{24}$ KANT, Immanuel. Fundamentação da metafísica dos costumes.São Paulo: Edições 70 Lda, 2007, p.77.

${ }^{25}$ SARMENTO, Daniel. op. cit. 2004. p.108.
} 
Para Alexandre de Moraes;

A dignidade é um valor espiritual e moral inerente a pessoa, que se manifesta singularmente na autodeterminação consciente e responsável da própria vida e que traz consigo a pretensão ao respeito por parte das demais pessoas, constituindo-se um mínimo invulnerável que todo estatuto jurídico deve assegurar, de modo que, somente excepcionalmente, possam ser feitas limitações ao exercício dos direitos fundamentais, mas sempre sem menosprezar a necessária estima que merecem todas as pessoas enquanto seres humanos."26

A dignidade humana é um valor supremo que engloba todos os direitos fundamentais do homem, inclusive o devido acesso à justiça. As partes, quando diante de um litígio, almejam uma solução e, via de regra, depositam ao poder judiciário tal tarefa.

$\mathrm{O}$ acesso à justiça sempre esteve atrelado ao princípio constitucional do devido processo legal, nos moldes do $\operatorname{art} .5^{\circ}, \mathrm{XXXV}$ da CF que transcreve que: "a lei não excluirá da apreciação do Poder Judiciário lesão ou ameaça a direito".

Entretanto, há de se convir que a definição trazida pela Carta Magna vigente é muito genérica e ampla. A definição de acesso à justiça não pode ser confundida com o simples direito de petição, pois se tal garantia se restringisse ao citado ato, o simples ingresso de uma ação estaria assegurando o alcance da justiça. $O$ acesso à justiça deverá ser acessível e aplicado a todo e qualquer cidadão, sendo de extrema necessidade que haja uma justiça concreta e não meramente formal.

A prestação do acesso à justiça esta intimamente ligada ao princípio da dignidade da pessoa humana, pois é através desta que o direito estará sendo materializado. Este é o posicionamento sustentado por Nunes:

É mediante o Poder Judiciário que é assegurada a efetividade dos direitos conferidos constitucional ou infra constitucionalmente, dessa forma, sem a adequada prestação jurisdicional impede-se a realização de todos os valores ético jurídicos que o referido princípio visa garantir. ${ }^{27}$

Nunes, no entanto, se limita a mencionar a respeito da prestação jurisdicional como fonte asseguradora do acesso à justiça, entretanto, é taxativo que uma vez não cumprido seu papel, estará violando garantias constitucionais.

\footnotetext{
${ }^{26}$ MORAES, de Alexandre. Direitos humanos fundamentais. 4.ed. São Paulo: Atlas, 2002, p. 60.

${ }^{27}$ NUNES, LuisAntonioRizzatto. 0 princípio da dignidade da pessoa humana: doutrina e jurisprudência. São Paulo: Saraiva, 2002.p. 49.
} 
No entanto, inúmeros são os obstáculos ao acesso à justiça que são tanto de natureza econômica, legal, social e cultural e para que haja uma mudança é necessário que se trabalhe todas essas vertentes.

Como frisa Cappeletti: "procedimentos complicados, formalismo, ambientes que intimidam, como o dos tribunais, juízes e advogados, figuras tidas como opressoras, fazem com que o litigante se sinta perdido, um prisioneiro num mundo estranho." 28

Admitir a falha da prestação jurisdicional e aceitar o auxílio de outros meios, tais quais os meios alternativos, é um avanço e certamente um ganho tanto para o Estado como para toda sociedade.

$\mathrm{Na}$ mediação o sentimento de adversidade sai de cena e a imagem de ganhador-perdedor é substituída por uma nova abordagem, baseado na cooperação e não mais na adversidade, ou seja, não há litigância.

As partes visualizam com a mediação o respeito aos seus princípios, seus valores e suas crenças na decisão, uma vez que são os conflitantes que elegem a decisão.

Se comparada a decisão judicial à composição consensuada entre as partes, percebe-se que a primeira tem por base uma linguagem terceira normativamente regulada. Ao contrário, a mediação desmancha a lide, descompõe-na nos seus conteúdos conflituosos, avizinhando os conflitantes que, portanto, perdem as suas identidades construídas antagonicamente. ${ }^{29}$

A mediação tende, assim, a desdramatizar o problema para que seja encarado de forma simplista, habilitando as partes a solucionarem por si seus problemas, transformando o confronto em algo colaborativo.

Tal método é capaz de renovar a cultura da sociedade, pois ao estimular as partes ao diálogo é capaz de incentivar a autonomia, vez que as próprias partes que elegerão sua decisão, auxiliando assim para com a pacificação social.

${ }^{28}$ CAPPELLETTI, Mauro. Acesso à justiça. Trad. Ellen Gracie Norhfleet. Porto Alegre: Fabris, 1988. p.24.

${ }^{29}$ SPENGLER, Fabiana Marion. A desinstitucionalização da família e a prática da mediação familiar no Brasil. In: DIAS, Maria Berenice. Direito das Famílias: contributo do IBDFAM em homenagem a Rodrigo da Cunha Pereira, São Paulo: Revista dos Tribunais, 2010, p. 289. 
Dessa maneira, a metodologia da mediação procura dar às pessoas autonomia e autodeterminação, conferindo-lhes a liberdade de decidir. ${ }^{30}$ Enquanto a via jurisdicional se apoia na adversidade.

O caminho a ser percorrido para atingir o nível da intercompreensão começa pela qualificada troca de informações, comunicação normalmente deteriorada, já que, inconscientemente, os mediandos comunicam-se pela linguagem do conflito - inadequada e destrutiva - em lugar da linguagem adequada e construtiva da intercompreensão, pois encontram-se tão frágeis que não conseguem despertar outros recursos pessoais mais adequados. ${ }^{31}$

Infelizmente a sociedade moderna não foi estimulada ou despertada para solucionar seus conflitos por si só ou por terceiro que não seja uma autoridade estatal, há a falsa percepção de que somente o judiciário poderá assegurar uma decisão justa, daí a imensa importância da ação estatal para que tais inverdades sejam alteradas e, muito embora a nova legislação já venha alterar tal cenário, muito ainda há que se fazer.

O princípio da dignidade humana "é o pressuposto da ideia de justiça humana, pois ela dita a condição superior do homem, independentemente de qualquer tipo de merecimento pessoal ou social. A motivação de seu merecimento é a própria vida."32

A dignidade humana só será respeitada quando permitir um acesso à justiça sem maiores delongas, sem maiores estresses e se preocupando principalmente com as consequências que tais atos ocasionarão aos envolvidos.

Face a tais alegações, há de se concluir que os meios alternativos de resolução de conflitos, em especial a mediação, ao respeitar a liberdade das partes em decidirem seus conflitos e aprimorando o diálogo das mesmas, estarão respeitando, integralmente, o principio da dignidade humana, que na maioria das vezes é desrespeitado quando da aplicação da via jurisdicional, pois a mediação tem a função de devolver as partes o que foi perdido, o caso a capacidade de dirimir conflitos.

\footnotetext{
${ }^{30}$ MUSZKAT, Malvida e, OLIVEIRA, Maria Coleta, UNBEHAUM, Sandra, MUSZKAT, Susana. op.cit., 2008, p. 22.

${ }^{31}$ BARBOSA, Águida Arruda, op. cit. 2015, p.38.

${ }^{32}$ PEREIRA, Rodrigo da Cunha. Princípios fundamentais norteadores do direito de família. 2.ed. São Paulo: Saraiva, 2012, p.115.
} 


\section{CONCLUSÃO}

O princípio da dignidade da pessoa humana, ora base de todo ordenamento jurídico, faz-se valer através de direitos fundamentais, podendo elencar nesse rol o princípio do acesso à justiça.

É garantia fundamental de todo cidadão a prestação da justiça, seja ela exercida através de qualquer meio, desde que assegure e garanta aos envolvidos, além da efetiva solução do litígio, a utilização de método menos gravoso ao envolvidos, que assegure o prazo razoável da resolução do conflito e, principalmente, que assegure a dignidade humana de todos os envolvidos.

A mediação por sua vez contém características importantíssimas para a preservação de tais direitos, celeridade, informalidade, sigilo, sendo capaz de restabelecer vínculos perdidos e, principalmente, desenvolver a capacidade das partes em dialogarem auxiliando para inocorrência de reincidência de conflitos.

Ocorre que infelizmente no Brasil há uma acentuada tendência para resolver o conflito através da via jurisdicional, cultura que deverá ser alterada, pois as benesses da utilização da mediação são inúmeras.

Cumpre ao Estado, com o poder que detém, estimular a sociedade, assim como incentivar a utilização de tal método, que só visa auxiliar o trabalho do órgão estatal, assegurando a dignidade humana dos conflitantes, garantindo, assim, o devido acesso à justiça.

\section{REFERÊNCIAS}

ARAÚJO, Nádia de. Arbitragem: a nova lei brasileira e a praxe internacional. São Paulo: LTr, 1997.

BARBOSA, Águida Arruda. Mediação familiar interdisciplinar. São Paulo: Atlas S/A, 2015.

BARBOZA, Jovi. Arbitragem no Brasil: solução amigável de conflitos. Maringá:Editora Projus.2009.

BARROSO, Luíz Roberto. A dignidade da pessoa humana no direito constitucional contemporâneo: a construção de um conceito jurídico à luz da jurisprudência mundial. Belo Horizonte: Fórum, 2013. 
BEZERRA, Paulo Cesar Santos. Acesso à justiça: um problema ético-social no plano da realização do direito. Rio de Janeiro: Renovar, 2001.

CABRAL, Marcelo Malizia. Os meios alternativos de resolução de conflitos: instrumentos de ampliação do acesso à justiça. Porto Alegre: Tribunal de justiça do estado do rio grande do Sul, Departamento de artes gráficas, 2013.

CAETANO, Luiz Antunes. Arbitragem e mediação: rudimentos. São Paulo: Atlas.2002.

CACHAPUZ, Rozane da Rosa. Arbitragem: alguns aspectos do processo e do procedimento na lei n 9.307/96. São Paulo: Editora de Direito, 2000.

CALMON, Petrônio. Fundamentos da Mediação e da Conciliação. Rio de Janeiro: Forense, 2007.

CAPPELLETTI, Mauro. Acesso à justiça. Trad. Ellen Gracie Norhfleet. Porto Alegre: Fabris, 1988.

CARMONA, Carlos Alberto. A arbitragem no processo civil brasileiro. São Paulo:

Malheiros.1993.

FIUZA, César. Teoria geral da arbitragem. Belo Horizonte: Del Rey, 1995.

FURTADO, Paulo. Juízo arbitral. Salvador: Nova Alvorada, 1.995.

GIORDANO, Consuelo Ares de. Mediación, conflictos y soluciones razonables. Mendonza:

Jurídicas cuyo, 2004.

GRUNSPUN, Haim. Mediação familiar: o mediador e a separação de cais com filhos. São Paulo:

LTR, 2000.

MARINONI, Luiz Guilherme. Tutela antecipatória e julgamento antecipado: parte incontroversa da demanda. 5.ed. São Paulo: Revista dos Tribunais, 2002.

MEDINA, Eduardo Borges de Mattos. Meios alternativos de solução de conflitos: cidadão na administração da justiça, Porto Alegre: Sergio Antonio Fabris Editor, 2004.

MOORE, Christopher. 0 processo de mediação: estratégias práticas para a resolução de conflitos. In: RODRIGUES JÚNIOR, Walsir Edson, A prática da mediação e o acesso à justiça. Belo Horizonte: Del Rey, 2006.

MORAES, de Alexandre. Direitos humanos fundamentais. 4.ed. São Paulo: Atlas, 2002.

MORAIS, José Luiz Bolzan de. Mediação e arbitragem: alternativas à jurisdição. Porto Alegre: Livraria do Advogado, 1999. 
MUSZKAT, Malvida E, OLIVEIRA, Maria Coleta, UNBEHAUM. Sandra, MUSZKAT, Susana. Mediação familiar transdisciplinar: uma metodologia de trabalho em situações de conflito de gênero. São Paulo: Summus, 2008.

NUNES, Luis Antonio Rizzatto. O princípio da dignidade da pessoa humana: doutrina ejurisprudência. São Paulo: Saraiva, 2002.

PEREIRA, Rodrigo da Cunha. Princípios fundamentais norteadores do direito de família. 2.ed. São Paulo: Saraiva, 2012.

RODRIGUES, Horácio Vanderlei. Acesso à justiça no direito processual brasileiro. São Paulo: Acadêmica, 1994.

RODRIGUES JUNIOR, Walsir Edson. A prática da mediação e o acesso à justiça. Belo Horizonte: Del Rey, 2006.

RUIZ, Ivan Aparecido. Estudo sobre mediação no Direito brasileiro: natureza jurídica e outros aspectos fundamentais. 2003. Tese, Pontifícia Universidade Católica de São Paulo.

SALES, Lilia Maria de Morais; RABELO, Cilana de Morais Soares. Meios consensuais de solução de conflitos: instrumentos de democracia. revista de informação legislativa, ano 46, n¹82, Brasilia, 2009.

,Justiça e mediação de conflitos. Belo Horizonte: Del Rey, 2004.

SERPA, Maria de Nazareth. Mediação de família. Belo Horizonte: Del Rey, 1999.

SIQUEIRA, Dirceu Pereira; OLIVEIRA, Flávio Luis (Orgs.). Acesso à justiça: uma perspectiva da democratização da administração da justiça nas dimensões social, política e econômica. Birigui: Boreal, 2012.

; OLIVEIRA, Flávio Luis (Orgs.). Constitucionalismo, democracia, procedimento e substância. Birigui: Boreal, 2013.

; CAMPOS SILVA, Nilson Tadeu Reis. Minorias e Grupos Vulneráveis: reflexões para uma tutela inclusiva. Birigui: Boreal, 2013.

SOUZA NETO, João batista de Mello. Mediação em juízo: abordagem prática para obtenção de um acordo justo. São Paulo: Atlas, 2000.

SPENGLER, Fabiana Marion. A desinstitucionalização da família e a prática da mediação familiar no Brasil. In: DIAS, Maria Berenice. Direito das Famílias: contributo do IBDFAM em homenagem a Rodrigo da cunha pereira, São Paulo: Revista dos Tribunais, 2010.

TAVARES, Fernando horta. Mediação e Conciliação. Belo Horizonte: Mandamentos, 2002. 
TRINDADE. Jorge, TRINDADE. Elise karam, MOLINARI. Fernanda. Psicologia judiciária para a carreira da magistratura. Porto Alegre: Livraria do Advogado, 2010.

ZAPPAROLLI, Celia Regina. A experiência pacificadora da mediação: uma alternativa contemporânea para a implementação da cidadania e da justiça. In: Mediação de conflitos: pacificando e previnindo a violência. São Paulo: Summus, 2003.

WARAT, Luis Alberto. 0 oficio do mediador. Florianópolis: Habitus, 2001. ; Luis Alberto. In: MEZZAROBA, Orides. Surfando na Pororoca: ofício do Mediador. Florianópolis: Fundação Boiteux, vol. III, 2004.

Recebido em: 21.11.2015 / Revisões requeridas em: 17.03.2016 / Aprovado em: 09.04.2016 